\title{
Isabel Dejardin, Captives en tragédie. La captivité au féminin sur les scènes antiques et modernes
}

\section{Monica Pavesio}

\section{(2) OpenEdition}

1 Journals

\section{Edizione digitale}

URL: http://journals.openedition.org/studifrancesi/7548

DOI: 10.4000/studifrancesi.7548

ISSN: 2421-5856

\section{Editore}

Rosenberg \& Sellier

\section{Edizione cartacea}

Data di pubblicazione: 1 décembre 2009

Paginazione: 617-618

ISSN: 0039-2944

\section{Notizia bibliografica digitale}

Monica Pavesio, «Isabel Dejardin, Captives en tragédie. La captivité au féminin sur les scènes antiques et modernes», Studi Francesi [Online], 159 (LIII | III) | 2009, online dal 30 novembre 2015, consultato il 09 janvier 2021. URL: http://journals.openedition.org/studifrancesi/7548 ; DOI: https://doi.org/10.4000/ studifrancesi.7548

Questo documento è stato generato automaticamente il 9 janvier 2021.

\section{(c) $(1) \ominus$}

Studi Francesi è distribuita con Licenza Creative Commons Attribuzione - Non commerciale - Non opere derivate 4.0 Internazionale. 


\title{
Isabel Dejardin, Captives en tragédie. La captivité au féminin sur les scènes antiques et modernes
}

\author{
Monica Pavesio
}

\section{NOTIZIA}

ISABEL DEJARDIN, Captives en tragédie. La captivité au féminin sur les scènes antiques et modernes, Saint-Genouph, Librairie Nizet, 2008, pp. 318.

1 Nel Seicento la figura della prigioniera emerge progressivamente come carattere dal retroscena drammatico antico per entrare a far parte del numero di figure importanti del paesaggio tragico europeo. Il teatro antico integrava la prigioniera agli altri personaggi drammatici, nel teatro moderno europeo il suo ruolo cresce di importanza e diviene autonomo.

Isabel Dejardin si interroga sul ruolo della cattività al femminile nel teatro antico e moderno, dalla prima prigioniera - Cassandra condotta in cattività ad Argo da Agamennone - alle eroine del teatro francese ed inglese secentesco. Lo scopo del volume è di determinare l'esistenza di alcune caratteristiche comuni alla situazione della cattività femminile nella tragedia e di interrogarsi quindi sulle relazioni fra questi personaggi ed il soggetto portato in scena.

3 La scelta del corpus delle opere da analizzare desta qualche perplessità: incomprensibile, per esempio, la scelta di soffermarsi unicamente sul teatro greco, pur riconoscendo l'importanza di Seneca sul teatro tragico moderno cinquecentesco e secentesco; altrettanto inspiegabili i limiti cronologici alla base della scelta delle tragedie francesi prese in esame - i sedici anni compresi fra il 1634, anno della pubblicazione della Sophonisbe di Mairet ed il 1650, anno dell'Andromède di Corneille, alla luce, soprattutto, della scelta delle tragedie inglesi, due opere di Dryden, composte nel 1672 e nel 1678, molto dopo, quindi, la data limite francese. Troppo limitato inoltre 
il corpus delle tragedie inglesi - due - perché possa essere ritenuto rappresentativo. Impensabile poi, nel voler fare un discorso esaustivo sul personaggio della prigioniera nel teatro antico e moderno, non soffermarsi sulle tragedie cinquecentesche e lasciar fuori completamente il teatro italiano, che ha avuto una grande importanza nella ricezione dei classici e nella creazione di modelli.

Dopo un capitolo preliminare consacrato alle scelte metodologiche, l'autrice analizza il trattamento drammatico della cattività al femminile, soffermandosi prima sulla dimensione poetica dei testi presi in esame, poi sulle modalità della messa in scena del personaggio della prigioniera. L'esame dei testi - pur nella limitatezza evidenziata del corpus - rivela la presenza di fenomeni ricorrenti che concernono il ruolo della prigioniera nei soggetti drammatici, nonché le scelte poetiche che sono alla base della loro messa in scena: fenomeni ricorrenti che danno origine alla nascita di un tipo tragico, che dal teatro antico passa al teatro moderno. L'interessante lavoro della Dejardin forse doveva limitarsi alla tragedia francese. Se lo scopo era, invece, di analizzare anche le modalità straniere della messa in scena della cattività, come si evince dal sottotitolo, avrebbe dovuto presentare un corpus allargato sia a livello cronologico sia a livello numerico. Anche il teatro latino, al quale si fanno solo brevi accenni, rimane un grande assente, in questo lavoro che sembra mancare delle basi necessarie per costruire un'indagine che avrebbe potuto dare ottimi risultati. 